DOI: $10.30519 /$ ahtr.508933

Advances in Hospitality and Tourism Research (AHTR)

\title{
THE EFFECT OF DYNAMIC PRICING ON HOLIDAY PURCHASE INTENTIONS: MODERATED MEDIATION ROLE OF PERCEIVED RISK
}

\author{
Edin Güçlü SÖZER ${ }^{1}$ \\ Faculty of Business and Administrative Sciences, Okan University, Turkey \\ ORCID: 0000-0003-4984-4629
}

\begin{abstract}
This study targets to measure the effect of dynamic pricing offers on the purchase intentions of consumers for a winter holiday by taking into consideration a moderated mediator role of perceived risk on this effect. The study employs an experimental design with discount level and timing of the offer (offer recency) as the manipulated conditions. The findings confirm that discount offers have positive direct effect and perceived risk has a negative direct effect on purchase intentions. The levels of discount and perceived risk, independently from each other, determine the level of purchase intentions. On the other hand, the effect of discount offers on purchase intentions is mediated by the perceived risk level of consumers. Finally, the timing of the discount offers moderates the effect of perceived risk on purchase intentions and eventually generates a moderated mediation role for perceived risk on the influence of discount offers on purchase intentions. Based on the findings of this study, some practical implications are provided.
\end{abstract}

\section{Article History}

Received 6 January 2019

Revised 18 February 2019

Accepted 21 February 2019

Keywords

dynamic pricing

discounts

perceived risk

purchase intentions

\section{INTRODUCTION}

Today, consumers benefit from the convenience of having many alternatives in their hand to use in their evaluations of products or services offered by the companies. This is the natural result of increasing number of companies competing in the market. Thanks to the adoption of Internet as a medium of both communication and transaction, consumers

\footnotetext{
1 Address correspondence to Edin Güçlü Sözer, Okan University, Faculty of Business and Administrative Sciences, Okan University, Istanbul, TURKEY. E-mail: edin.sozer@okan.edu.tr
} 
can access the information on many alternatives at once, which in turn, helps them to increase the efficiency of their decision-making process. Ease of access to the information about all possible alternatives in this highly competitive market environment make consumers more demanding and selective in their product or service choices. The reflection of this new dynamic to the companies is twofold.

First, companies have difficulty to convince customers in this intensively competitive market. Among the alternatives they evaluate, when they have similar offers, price level becomes one of the components which consumers are generally sensitive about. In order to transform this sensitivity into their advantage, marketers try to increase the value perception of consumers by approaching them with several cues such as sales promotions in a price discount format (Taylor, 2001). Companies use this tool to generate positive consumer attitudes towards their brand and convince target consumer to try or purchase their products or services ( $\mathrm{Yi}$ \& Yoo, 2011). Thus, price discounts are one way how companies cope with the difficulty of acquiring new customers. As a member of marketing communication mix, sales promotions and especially price discounts constitute a considerable share of the marketing budgets (Teng, 2009). On the other hand, when we consider that many sales promotion strategies do not provide the desired effectiveness, due to the accountability issue, markets need to understand very well the underlying dynamics in order to make better decisions (Grewal et al., 1998). Thus, marketers need to understand whether the price discount offers will shape consumer attitudes and behavior in a desired way.

The second difficulty that the companies face is related to managing the demand in an optimum way to prevent overstock, idle capacity, unbalanced cash flows and consequently to maximize the revenue and profit. Traditional pricing strategies such as uniform, competitive and cost-plus pricing strategies, have difficulty in responding effectively to changing market demand conditions (Sahay, 2007). Under uniform prices companies fix the price for a period and do not change it till the end of the period regardless of changing market conditions (Farahmand \& Chatterjee, 2008). Competitive pricing strategy requires companies setting their prices based on their peer group competitors (Enz et al., 2009). Finally, under cost-plus pricing strategy companies apply a profit margin on the top of the cost of the product to set the price without taking into consideration other market-based factors (Sahay, 2007). Companies react to changing market conditions by implementing dynamic pricing strategies which involves the determination of different prices to the same 
products considering the change in their status (Liu et al., 2008). Therefore, using dynamic pricing, companies adjust their prices in response to changing marketplace conditions (Dimicco et al., 2003). As a method of optimizing the price, models of dynamic pricing strategies incorporate demand elasticities, forecasted demand and competitor prices to decide on optimal prices and eventually maximize the revenue (Cross et al., 2009). Thus, dynamic pricing helps companies to sell their products at the right time and at the right price to their target consumers (Kimes, 2002). The applications of dynamic pricing are dependent on the product categories. For example, in perishable product categories, as the product bear the risk of being outdated and the demand is conditioned on shelf life, dynamic pricing works based on aging factor (Adenso-Diaz et al., 2017). Thus, prices are offered on the decreasing trend towards the end of the shelf life. On the other hand, lodging industry is one of the playgrounds where the employment of dynamic pricing strategies is fully justified due to the several reasons. First, the market demand level in the industry is not stable due to the seasonal as well as economic effects. Thus, continuous adjustment of prices to changing market conditions is required by discounting the rates to level the occupancy rates in low demand times or to steal the market share in normal conditions (Enz et al., 2009). Second, as the industry have some availability issue with perishable assets such as rooms, occupancy rates should be maximized by managing the demand (Abrate et al., 2012). Due to these reasons, dynamic pricing strategies are widely used in the lodging industry for the purposes of revenue management based on the availability and demand factors (Bayoumi et al., 2013). In the practices of this industry, the price may follow an increasing or decreasing trend depending on the availability of rooms as it diminishes or remains the same throughout the period. Thus, hotel reservations made earlier may benefit from discounted prices since there are more available rooms at the time of early reservation compared to the times closer to the planned check-in date. This inter-temporal effect on price offerings is an important feature of dynamic pricing offerings in the lodging industry.

Due to the importance of the dynamic pricing subject for reaching at successful bottom line results, marketers need to understand the underlying dynamics of how consumers react to dynamic pricing practices and be able to set the optimum price levels for different temporal distance and demand level conditions. There are several studies which focused on dynamic pricing concept. These studies can be classified into two broad categories including studies which generated dynamic pricing models 
(Feng \& Xiao, 2000; Gallego \& Ryzin, 1994; Zhao \& Zheng, 2000) and those studies which investigate the effects of dynamic pricing applications on different aspects of consumer behavior (Haws \& Bearden, 2006; Levin et al., 2009; Rohani, 2012). Although there are vast number of studies which focused on the effect of dynamic pricing on consumer behavior, to the best of our knowledge, there is a lack of studies which mainly focus on the effects of price discounts on purchase intentions in a dynamic pricing context taking into consideration the role of consumers' perceived risk and the timing of the offer. Perceived risk is a broad concept which was the subject of many studies in the literature. Due to the service-based nature of the lodging industry, the uncertainty about the consequences of a purchase decision is high and in general, when the uncertainty level increases, also the perceived risk level increases (Chakrabarti \& Baisya, 2009). This makes the perceived risk an important feature of the decisionmaking process in this industry (Roehl \& Fesenmaier, 1992). Combining the inter-temporal nature of dynamic pricing offers and the importance of perceived risk in consumer decision process in a service-based industry, the relationship between inter-temporal price offers in a discount format, the perceived risk level of consumers associated with the purchase situation and their purchase intentions in a dynamic pricing context needs to be investigated.

In this perspective, this study targets to fill a gap in the marketing literature by measuring the effects of dynamic pricing offers on the purchase intentions taking into consideration the roles of perceived risk and inter temporal effects of offer timing in the hospitality context. It is proposed that offering discounts will generate higher levels of purchase intentions and this effect will be mediated by the perceived risk of consumers related to the purchase of international holiday package. It is also proposed that the timing of the offer will have a moderating role on the effect of perceived risk on purchase intentions. This will eventually lead to the moderated mediation role of perceived risk on the effect of discount offering on purchase intentions.

\section{DYNAMIC PRICING AND PURCHASE INTENTIONS}

The advance in technologies and especially the rapid diffusion of internet provides several opportunities for companies and consumers in their interactions. Companies benefit from the availability of these advanced and cost-effective technologies when they set prices for the goods or services they offer. Due to the lack of information on demand information, 
large amount of investment required setting the technological infrastructure including hardware and software, and the high transaction costs of changing the prices, companies were applying static pricing and were forced to fix their prices for a long period of time (Elmaghraby \& Keskinocak, 2003). Today, the new technologies support companies to set their prices in a dynamic way by taking into consideration different customer needs, characteristics, and the availability of goods or services. They can acquire these skills of yield management and be able to set the right prices dynamically in a way that they offer the right product, to the right consumer, at the right time with the right prices (Kimes, 2002). Therefore, dynamic pricing considers the time factor in pricing and it is related with the pricing of a product overtime (Chenavaz et al., 2011). In other words, it is an inter-temporal discrimination of price by taking into consideration the uncertainty of future demand (Dasu \& Tong, 2010).

Dynamic pricing, as a concept which attracted considerable attention of researchers from several disciplines including marketing, economics and operations, was the subject of many studies in the literature (Dong et al., 2008). However, with full respect to all contributions made by the previous studies, the focus of this one will be on the review of underlying factors influencing dynamic pricing decisions of companies, forms of dynamic pricing and its effects on consumer behavior in the context of finite inventories, such as the offers in tourism sector.

Tourism sector is a dynamic system having distinguishing characteristics (Croes \& Semrad, 2012). Some of these unique characteristics are fixed and perishable room supply, uncertainty in demand and high operational fixed costs which collectively lead to continuous price adjustments (Corgel, 2004). The microeconomic theory, which presents the relationship between price and demand based on the downward sloping demand curve, suggests that when price decreases, the quantity demanded increases in cases of other factors hold constant (Enz et al., 2004). Taking the dynamic structure of the industry and dynamics of price and demand relations presented by the microeconomic theory into the dynamic pricing practices, we can conclude that hotel management confronts with both an inelastic room supply in a short-run and a downward sloping demand curve due to the seasonality effects which make them to set up some expectations about the rates that can be applied (Bull, 1997). However, these expected rates change overtime due to the different levels of demand leading to a continuous price adjustment and consequent fluctuations, which at the end bring the equilibrium by 
changing the demand patterns (Croes \& Semrad, 2012). Therefore, companies in the tourism sector often apply dynamic pricing strategies for the purpose of demand and revenue management as they have finite inventories. The availability of online tools supported the wide range adoption of dynamic pricing in this industry since they facilitate real time adjustment of prices based on the room availability, inventory level and competitive prices (Viglia et al., 2016).

Dynamic pricing decisions are generally influenced by three factors, namely learning, diffusion and network effects, and these factors individually and collectively determine the actual as well as intertemporal pricing decisions of the companies (Chenavaz et al., 2011). Thus, the learning effect, a product of experience which leads to increasing productivity (Arrow, 1962), diffusion effect, explained as the increasing probability of sales due to the increasing penetration into the market (Bass, 1969) and finally network effects, explained as the dependence of the value of a product for the consumer on the number of users of that product (Economides, 1996) influence the dynamic pricing decisions of companies. Depending on the characteristics of the market whether the offers are replenishment or not, dependent to demand or not and whether customers are myopic or strategic, companies face different versions of dynamic pricing cases (Elmaghraby \& Keskinocak, 2003). As a result of the interaction between the above-mentioned factors and characteristics, companies implement various types of inter-temporal pricing strategies (Jorgensen, 1986). Some companies implement a skimming pricing policy dynamically which consists of applying higher prices in the beginning and then decreasing the prices gradually. Products which are sensitive to network effects may be regarded as important determinants of this policy as they provide the opportunity of benefiting from the inter-temporal surplus of consumers (Mahajan et al., 1990). On the other hand, some companies implement a penetration pricing strategy dynamically, which consists of applying lower prices in the beginning and then increasing the prices gradually as the market penetration or sales reach a satisfactory level. This strategy works well in cases of new introductions to the market and when early adopters have strong influence on follower consumers (Chenavaz et al., 2011).

There are several studies which developed models for explaining the dynamics of the relationship between price, time and demand level. Gallego and Ryzin (1994) proposed a model estimating the optimum pricing policy as a function of the number of rooms available and the length of time horizon. Similarly, Badinelli (2000) focused on small hotels 
and proposed a model based on the vacancies and time factors. The findings of the above-mentioned studies confirm the importance of room availability in defining the dynamic pricing strategies. Generally, with finite inventories, tourism companies implement a dynamic penetration pricing strategy involving the setting of prices lower when there is high availability of rooms and increase the prices as the availability shrinks.

From the consumers' side, as it is confirmed by the study of Abrate et al. (2012), customers who did not book earlier, in a case of high demand, they will have limited room choices and they will be convinced to pay higher amounts. According to Zhao and Zheng (2000), the optimal price for a given inventory level decreases over time in cases of decrease in the willingness of consumers to pay a premium. They conclude that this is not the case in the travel services. Thus, when the waiting costs are high for the customers, they will prefer to purchase upfront since they are risk averse and they decide when to buy the products (Su, 2007; Liu \& Ryzin, 2008). One way of generating waiting costs for the customers in order to boost early reservations, is to implement a dynamic penetration price strategy; start with low prices and raise the prices gradually depending on the occupancy rate. Discounted prices are effective tools for controlling the occupancy rate with early reservations (Koide \& Ishii, 2005). In this perspective, we can state that the price level and occupancy rate information are the two important factors which drive the demand for the rooms (Qu, et al., 2002).

Previous research conducted on the effect of discounted prices on purchase intentions and sales confirm the significant and positive effects in different context and situations. Kopalle et al. (1999) reported the significant and positive effect of sales promotions in the short-terms sales and concluded that sales promotions can be implemented more often in cases where consumers are price sensitive. As one of the types of sales promotions, discounted prices are found to have positive effects directly on purchase intentions (Santini et al., 2015; Chao \& Liao, 2016). Additionally, Grewal et al. (1998) reported the indirect positive effect of discounted prices on purchase intentions through perceived value of the offering. Enz et al. (2004) compared the effect of discounted offers on occupancy rates and financial performance and concluded that discounted offers generate higher occupancy rates (short-term effect) while decreasing the revenue performance vis-a-vis competitors in the market. 
In the light of previous studies and the associated findings on the effects of dynamic pricing and price discounts on consumer behavior, we propose the following hypotheses:

H1: Discount offers will have a direct positive effect on purchase intentions.

$\mathrm{H} 2$ : Increasing levels of discounts will lead to increasing levels of purchase intentions.

\section{DYNAMIC PRICING, PERCEIVED RISK AND PURCHASE INTENTIONS}

Perceived risk is an important factor of consumer decision making process since the consumers' perception about the type and degree of risk involved in a situation affects their behavior (Cox \& Rich, 1964). The concept is defined as the subjective probability of loss derived from unexpected and uncertain consequences of a purchase situation (Bauer, 1960). Due to its importance in consumer decision making process, it was the subject of many studies since several decades (Mitchell, 1999).

Perceived risk is a multidimensional construct composed of two components including uncertainty about and consequences of an action (Lin \& Fang, 2006). Thus, when the uncertainty about the consequences of an action is high in a purchase situation, perceived risk becomes also higher (Hong \& Cha, 2013). Taking into consideration the intangibility dimension of services such as hospitality, perceived risk is more intense since consumers do not have the opportunity to test the performance before purchasing it (Mitra et al., 1999). Previous studies in the literature identified six main dimensions of perceived risk construct including performance risk, financial risk, physical risk, convenience risk, social risk and psychological risk, which may derive as the outcomes of a purchasing action (Murray, 1991). This study focused on the moderating effect of performance risk dimension on the influence of discount offers on purchased intentions.

Consumers generally try to maximize the value they receive when they evaluate product and service alternatives and prefer the goods or services with higher perceived value (Dodds \& Monroe, 1985). Value is defined as the difference between what you get (benefits) and what you give (costs) as a result of a purchasing situation and consumers make the comparison of these benefits and costs before making their final decisions 
(Heskett et al., 1994). Previous studies confirm the positive effect of perceived value on purchase intentions (Chang \& Wildt, 1994). The relationship between the discount offers and perceived risk can be explained based on mental accounting theory which suggests that consumers make their decisions based on the total utility generated by the transaction (Kim et al., 2005). Taking into consideration that the price of the product or service is a part of the total perceived utility, when there is a discount on it, this situation leads to the increase on the total perceived value of the transaction by maximizing the financial benefits and, at the same time, reducing the perceived risk by decreasing the amount of possible losses. Previous studies in the literature confirm the negative effect of sales promotions such as discounts on the perceived risk level of consumers (Garretson \& Clow, 1999). In the light of the theoretical background and previous findings, the following hypotheses are proposed:

H3: Discount offers will negatively affect the perceived risk of consumers.

H4: Increasing level of discount offers will lead to decreasing levels of perceived risk.

As consumers perceive some level of risk in almost any situation depending on the context and situation they are involved in, this level of risk is an important determinant of the intention to purchase, which is in turn an indicator of the actual purchase decision (Tan, 1999). Previous studies in the literature confirm that there is an inverse relationship between the perceived risk level and purchase intentions of consumers in such a way that when perceived risk level increases, this leads to decreasing levels of purchase intentions (Bhukya \& Singh, 2015; Hashim et al., 2017; Xie, 2017; Wood \& Scheer, 1996). In the context of hospitality and tourism, the same negative effect of perceived risk on purchase intentions is also confirmed by the previous studies in the literature (Mitchell \& Vassos, 1997; Kim et al., 2005). In the light of the existing findings in the literature, it is believed that perceived risk level of consumers will have a direct and negative effect on purchase intentions. Moreover, this negative direct effect of perceived risk is also expected to have a mediating role on the positive effects of discount offers on purchase intentions. In this perspective, the following hypotheses are proposed:

H5: Perceived risk level will negatively affect purchase intentions.

H6: The effect of discount offers on purchase intentions will be mediated by the perceived risk level. 
H7: Increasing levels of discount offers will indirectly lead to increasing levels of purchase intentions through perceived risk.

\section{PERCEIVED RISK, OFFER RECENCY AND PURCHASE INTENTIONS}

Perceived risk represents the subjective evaluations of a possible loss in a purchase situation and this directly influences the purchase intentions of consumers (Sweeney et al., 1999; Kim et al., 2005). At the same time, this perception about the risk inherent in a situation is not static and varies over time (Doss et al., 2006). Thus, there is a time effect on the perceived risk which leads consumers to make inter temporal preferences. These inter temporal preferences affect consumers' behavior and are one of the determinants of their purchase decisions (Bartels \& Urminsky, 2015; Shapiro, 2005).

The literature related with the dynamics of inter temporal decision making has grown extensively in the last 25 years (Zauberman \& Urminsky, 2016). The algorithms of all decision-making models generated in those studies are defined by their temporal discounting function which can be defined as the comparison between the subjective values generated by delayed and immediate rewards for the consumers (Namboodiri et al., 2014). Thus, the timing of the reward or transaction directly relates with the perceived value of the person involved in the situation. When consumers perceive the duration longer, they tend to discount the outcomes more steeply than those durations which are perceived shorter (Kim \& Zauberman, 2009). This eventually leads to the depreciation of perceived value in cases of longer waiting periods to get the benefits of the transaction.

When we consider the situation in the tourism context, subjective value of purchasing a holiday earlier is expected to be lower compared to purchasing it on spot due to the discounting of expected value. Thus, the timing of the offer is expected to moderate the relationship between the perceived risk and purchase intentions of consumers by altering the perception of value expected as a result of the purchasing the holiday. Moreover, based on the theoretical background as well as findings in the previous studies mentioned above, this situation is expected to result in a moderated mediation role of perceived risk on the effect of discount offers on purchase intentions of consumers. 
In the light of the theoretical background and the findings in the literature we propose the following hypothesis:

H8: Offer recency will moderate the relationship between perceived risk and purchase intentions.

H9: Discount offers will have a conditional indirect effect on purchase intentions through the moderated mediation of perceived risk.

\section{RESEARCH METHODOLOGY}

\section{Research design}

This study has implemented an experimental design targeting to measure the effect of different discount levels offered on the purchase intentions of consumers, by taking into consideration the moderated mediation role of perceived risk. The study included two manipulated factors, namely discount level and timing of the offer (offer recency). The subjects were chosen among the citizens of Istanbul city who regularly go to international ski resorts each year with their families. Total number of questionnaires collected was 675 .

Participants were divided into three main groups with equal number of subjects in each group. All groups were presented a scenario describing the case which they were about to decide to purchase a oneweek ski resort package in Austria for their regular winter holiday. The picture of the hotel, one-week package details and offered price were also included in the scenario. The ski resort and other information employed in the scenario were hypothetical and developed for the purpose of this study. Thus, there were no prior knowledge of consumers about the ski hotel. The scenario text was also included a warning about the limited number of rooms left. Each group was presented with different discount level conditions. First group was presented with no discount (Discount $\mathrm{N}_{\mathrm{N}}$ ) at all, just the regular price. Second group was presented with the regular price and 15\% discount (Discountmid) applied to it. Finally, the third group was presented with the regular price and 30\% discount (Discount ${ }_{H i g h}$ ) applied.

Each experiment group with different discount conditions was further divided into three sub-groups, with equal number of subjects for the introduction of the second manipulation factor- the offer recency. In each discount condition scenario, subjects were presented with additional 
information regarding the time left for the holiday trip. In the first discount scenario (Discount $\mathrm{N}_{\mathrm{N}}$ ), three sub-groups generated were presented with three different offer recency conditions. The first subgroup was presented a case where the winter holiday trip was scheduled to start one week after the purchase (Offerspot). Second sub-group was presented a case where the winter holiday was about to start after three months following the purchase transaction (Offermid-Term). Finally, third sub-group was presented a case where the winter holiday was about to start after six months following the purchase transaction (OfferEarly Bird). The same sub-groups of offer recency condition were created and applied for the remaining two groups of discount conditions.

Following the introduction of the scenarios containing different discount conditions and the offer recency sub-conditions under each discount conditions, subjects were presented with the statements measuring their perceived risk about the purchasing situation as well as their purchasing intentions. Table 1 summarizes the details of the experimental design applied in this study.

Table 1. Experimental Design

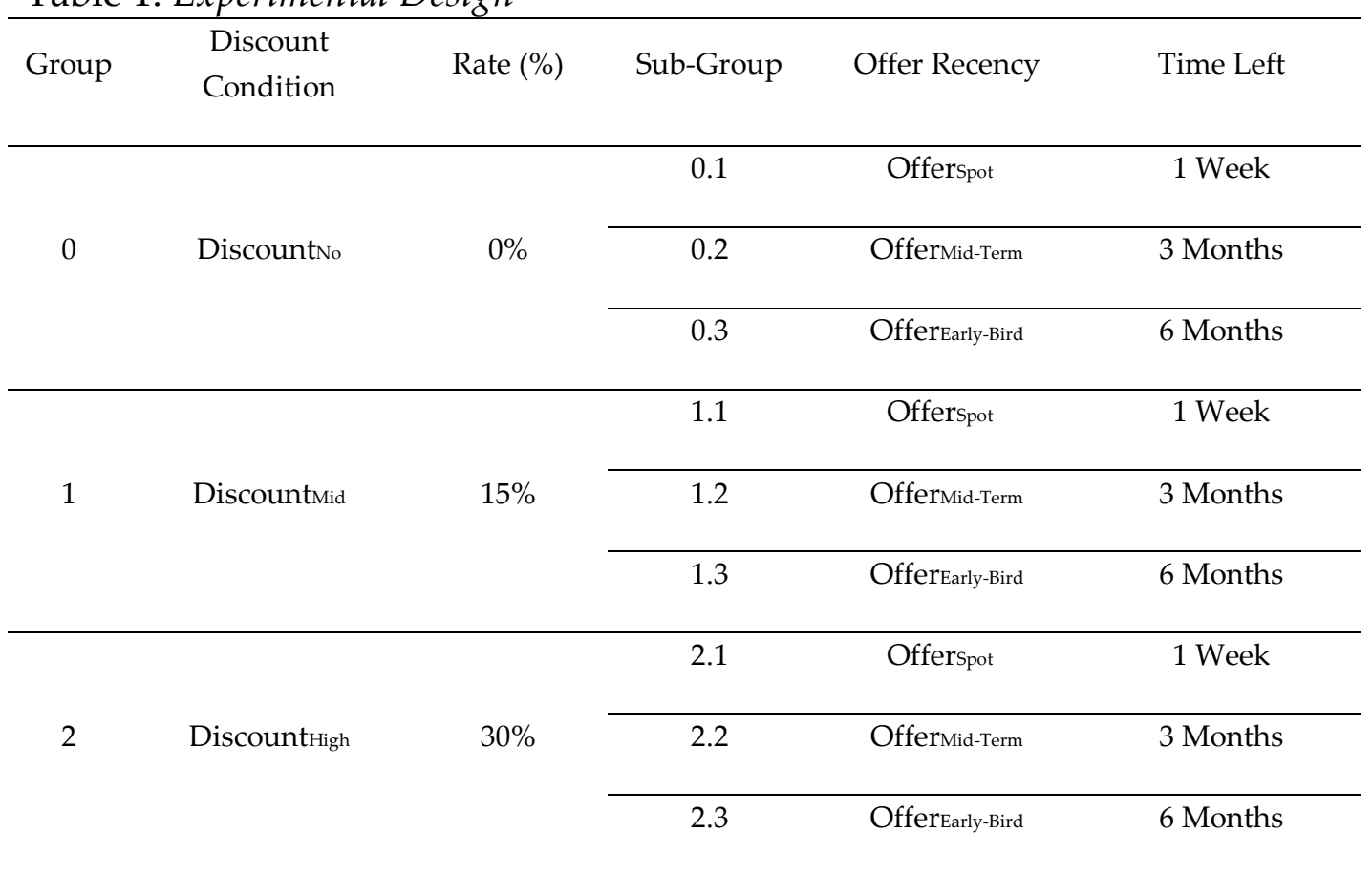




\section{Operationalization of variables}

Perceived risk and purchase intentions scales were borrowed from the corresponding literature and necessary adjustments were made to these scales for the purpose of this study. Perceived risk scale was borrowed from the studies of Campbell and Goodstein (2001) and Noseworth and Trudel (2011). This four items nine points semantic differential scale was developed to measure a person's overall perceived risk regarding a purchase situation. The reliabilities reported for the scale were between 0.91 and 0.79 in these two studies, respectively. The scale employed in the study was adjusted to express the perceived risk as a function of offer period and converted into five points.

Table 2. Perceived Risk and Purchase Intention Scales

\begin{tabular}{|c|c|c|}
\hline \multicolumn{3}{|c|}{ Perceived Risk } \\
\hline \multicolumn{3}{|c|}{ How do you consider the risk of purchasing the holiday package from this international ski resort? } \\
\hline $\begin{array}{l}\text { Not At All } \\
\text { Risky }\end{array}$ & $(\ldots) \ldots \ldots \ldots \ldots \ldots(\ldots) \ldots \ldots \ldots \ldots \ldots \ldots(\ldots) \ldots \ldots \ldots \ldots \ldots(\ldots) \ldots \ldots \ldots \ldots \ldots(\ldots)$ & $\begin{array}{l}\text { Extremely } \\
\text { Risky }\end{array}$ \\
\hline $\begin{array}{l}\text { Not At All } \\
\text { Concerned }\end{array}$ & $(\ldots) \ldots \ldots \ldots \ldots \ldots(\ldots) \ldots \ldots \ldots \ldots \ldots \ldots(\ldots) \ldots \ldots \ldots \ldots \ldots(\ldots) \ldots \ldots \ldots \ldots \ldots(\ldots)$ & $\begin{array}{l}\text { Highly } \\
\text { Concerned }\end{array}$ \\
\hline $\begin{array}{l}\text { Very } \\
\text { Unimportant }\end{array}$ & $(\ldots) \ldots \ldots \ldots \ldots \ldots(\ldots) \ldots \ldots \ldots \ldots \ldots \ldots(\ldots) \ldots \ldots \ldots \ldots \ldots(\ldots) \ldots \ldots \ldots \ldots \ldots(\ldots)$ & $\begin{array}{c}\text { Very } \\
\text { Important }\end{array}$ \\
\hline $\begin{array}{l}\text { Not At All } \\
\text { Worried }\end{array}$ & $(\ldots) \ldots \ldots \ldots \ldots \ldots(\ldots) \ldots \ldots \ldots \ldots \ldots \ldots(\ldots) \ldots \ldots \ldots \ldots \ldots(\ldots) \ldots \ldots \ldots \ldots \ldots(\ldots)$ & $\begin{array}{l}\text { Very } \\
\text { Worried }\end{array}$ \\
\hline \multicolumn{3}{|c|}{ Purchase Intention } \\
\hline \multicolumn{3}{|c|}{ How likely are you to buy the ski resort holiday package on offer? } \\
\hline $\begin{array}{l}\text { Highly } \\
\text { Unlikely }\end{array}$ & $(\ldots) \ldots \ldots \ldots \ldots \ldots(\ldots) \ldots \ldots \ldots \ldots \ldots \ldots(\ldots) \ldots \ldots \ldots \ldots \ldots(\ldots) \ldots \ldots \ldots \ldots \ldots(\ldots)$ & $\begin{array}{l}\text { Highly } \\
\text { Likely }\end{array}$ \\
\hline & How probable is it that you will purchase the product on offer? & \\
\hline $\begin{array}{l}\text { Highly } \\
\text { Improbable }\end{array}$ & $(\ldots) \ldots \ldots \ldots \ldots \ldots(\ldots) \ldots \ldots \ldots \ldots \ldots \ldots(\ldots) \ldots \ldots \ldots \ldots \ldots(\ldots) \ldots \ldots \ldots \ldots \ldots(\ldots)$ & $\begin{array}{l}\text { Highly } \\
\text { Probable }\end{array}$ \\
\hline & How certain is that you will purchase this product? & \\
\hline $\begin{array}{l}\text { Highly } \\
\text { Uncertain }\end{array}$ & $(\ldots) \ldots \ldots \ldots \ldots \ldots(\ldots) \ldots \ldots \ldots \ldots \ldots \ldots(\ldots) \ldots \ldots \ldots \ldots \ldots(\ldots) \ldots \ldots \ldots \ldots \ldots(\ldots)$ & $\begin{array}{l}\text { Highly } \\
\text { Certain }\end{array}$ \\
\hline & What chance is there that you will buy this product? & \\
\hline $\begin{array}{l}\text { No Chance } \\
\text { At All }\end{array}$ & $(\ldots) \ldots \ldots \ldots \ldots \ldots(\ldots) \ldots \ldots \ldots \ldots \ldots \ldots(\ldots) \ldots \ldots \ldots \ldots \ldots(\ldots) \ldots \ldots \ldots \ldots \ldots(\ldots)$ & $\begin{array}{l}\text { Very Good } \\
\text { Chance }\end{array}$ \\
\hline
\end{tabular}

Purchase intentions scale was borrowed from the studies of Chandran and Morwitz (2005). This semantic differential scale with four items and seven points was developed to measure a person's stated likelihood of buying a product that is being offered in a purchase situation. The authors reported a reliability score of 0.89 in their study. The scale employed in the study was adjusted to express the purchase 
intention of consumers regarding the discount level offered and it was converted into five points. The statements and scale items for perceived risk and purchased intentions are summarized in Table 2.

The modifications which were made to the borrowed scales led to the need of confirming the reliability of each scale employed. The reliabilities of the scales were tested by conducting a principal component analysis. The results of the principal component analysis confirmed the internal consistencies of all scales employed in the study. The analysis resulted in the extraction of two components and high level of internal reliabilities for each construct employed. The results of the principal component analysis are summarized in Table 3.

Table 3. Results of the Principal Component Analysis

\begin{tabular}{|c|c|c|c|c|c|}
\hline Component & Construct & Coverage & Items & Loadings & $\alpha$ \\
\hline 1 & $\begin{array}{l}\text { Perceived } \\
\text { Risk }\end{array}$ & $\begin{array}{l}\text { Measures consumers' overall perceived } \\
\text { risk with regard to a purchase situation. }\end{array}$ & 4 & 0.467 & 0.978 \\
\hline 2 & $\begin{array}{l}\text { Purchase } \\
\text { Intentions }\end{array}$ & $\begin{array}{l}\text { Measures consumers' stated likelihood of } \\
\text { buying a particular product that is being } \\
\text { offered in a purchase situation. }\end{array}$ & 4 & 0.311 & 0.796 \\
\hline
\end{tabular}

\section{Analysis}

Due to its common employment in studies which measure moderation, mediation and moderated mediation effects, PROCESS SPSS macro was used in order to test the moderated mediation model and associated hypothesis related to the relative total, direct and indirect effects of discount levels on purchase intentions through perceived risk (mediation effect) and relative conditional indirect effects of discount levels on purchase intentions through the moderated mediator role of perceived risk by offer recency (moderated mediation effect).

PROCESS is a modeling tool generated by Andrew F. Hayes to be used in SPSS and SAS statistical package programs. It is based on the observed variable OLS and logistic regression path analysis and this tool is widely used in several disciplines including social and health sciences. PROCESS estimates the direct and indirect effects of independent variables including single and multiple mediator models (parallel and 
serial), interactions in moderation models and conditional indirect effects in moderated mediation models (Hayes, 2018). It provides the asymmetric bootstrap confidence interval (CI) estimates for the measurement of both relative indirect and relative conditional indirect effects (Hayes \& Preacher, 2013).

\section{FINDINGS}

\section{Total, Direct and Indirect Effects of Discount Offer on Purchase Intentions}

The results of the analysis for measuring the total, direct and indirect effects of discount level on consumer purchase intentions, led to the generation of three estimation models summarized in Table 4.

Table 4. Total, Direct and Indirect Effects of Discount on Purchase Intentions

\begin{tabular}{|c|c|c|c|c|c|c|c|c|c|}
\hline \multirow{3}{*}{ Antecedents } & \multicolumn{3}{|c|}{ Model 1} & \multicolumn{3}{|c|}{ Model 2} & \multicolumn{3}{|c|}{ Model 3} \\
\hline & \multicolumn{3}{|c|}{ Purchase Intention (Y) } & \multicolumn{3}{|c|}{ Perceived Risk (M) } & \multicolumn{3}{|c|}{ Purchase Intention $(\mathrm{Y})$} \\
\hline & Coefficient & SE & $\mathrm{p}$ & Coefficient & SE & $\mathrm{p}$ & Coefficient & SE & $\mathrm{p}$ \\
\hline Discountmid & 0.822 & 0.065 & $<.001$ & $\mathrm{a}_{1}-1.000$ & 0.551 & $<.001$ & $\mathrm{c}^{1_{1}} \quad 0.491$ & 0.076 & $<.001$ \\
\hline DiscountHigh & c2 1.834 & 0.064 & $<.001$ & a2 -2.173 & 0.550 & $<.001$ & $c^{1}{ }_{2} \quad 1.114$ & 0.113 & $<.001$ \\
\hline $\begin{array}{l}\text { Perceived } \\
\text { Risk (M) }\end{array}$ & ------ & ------- & ------ & ------ & ------ & ------ & $b-0.331$ & 0.043 & $<.001$ \\
\hline \multirow[t]{3}{*}{ Constant } & 2.453 & 0.046 & $<.001$ & $\operatorname{Im} \quad 4.067$ & 0.389 & $<.001$ & Iy 3.801 & 0.182 & $<.001$ \\
\hline & \multicolumn{3}{|c|}{$\mathrm{R}^{2}=.5473$} & \multicolumn{3}{|c|}{$\mathrm{R}^{2}=.6993$} & \multicolumn{3}{|c|}{$\mathrm{R}^{2}=.5835$} \\
\hline & \multicolumn{3}{|c|}{$\mathrm{F}(2,673)=407, \mathrm{p}<.001$} & \multicolumn{3}{|c|}{$\mathrm{F}(2,673)=782, \mathrm{p}<.001$} & \multicolumn{3}{|c|}{$\mathrm{F}(3,672)=314, \mathrm{p}<.001$} \\
\hline
\end{tabular}

Model 1 estimates the total relative effect of different discount levels on the purchase intentions of consumers. This model shows the sum of direct and indirect effects of discount offers on purchase intentions. Model 2 estimates the direct effect of discount offers on perceived risk. Finally, Model 3 estimates the direct effects of both discount offers and perceived risk on purchase intentions.

Starting with the direct effects of discount offers on purchase intentions, as it is confirmed by Model 3, discount offers have significant positive direct effects on purchase intentions $\left(\mathrm{R}^{2}=0.583, \mathrm{~F}(3,672)=313\right.$, $\mathrm{p}<0.001)$. Thus, we accept H1. The results also confirm the significant and higher positive direct effect of middle level discount offers (Discountmid) on purchase intentions compared to cases with no discount offers $(B=$ 
0.491, $\mathrm{p}<0.001$ ). When the discount level is higher (DiscountHigh), this also leads to significant and higher positive direct effect on purchase intentions compared to cases with no discount offers $(B=1.114, p<0.001)$. This result leads us to support H2. Model 3 also estimates the direct effect of perceived risk on purchase intentions and confirms the significant negative effect $\left(R^{2}=0.583, F(3,672)=313, p<0.001\right)$. Those consumers who are offered the same amount of discount or no discount at all and the same time perceive the risk higher, are estimated to show lower level of intention to purchase $(B=-0.331, p<.001)$. In the light of these results we accept H5.

Model 2 estimates the effect of different discount levels on perceived risk compared to cases with no discount offers. The results of the model confirm that discount offers have significant effect on the perceived risk levels of consumers $\left(\mathrm{R}^{2}=0.699, \mathrm{~F}(2,673)=782, \mathrm{p}<0.001\right)$. This result leads us to support $\mathrm{H} 3$. Moreover, when the level of discount offering increases, its negative effect on the perceived risk of consumer becomes stronger. Thus, when consumers are offered middle level discount offers (Discount $\mathrm{Mid}$ ), this leads to the generation of lower level of perceived risk $(B=-1.000, p<0.001)$ compared to the cases with no discount offers. On the other hand, higher level of discount offers (Discount ${ }_{H i g h}$ ) generate even more stronger negative effects on the perceived risk of consumers compared to cases with no discount offers $(B=-2.1729$, $\mathrm{p}<0.001)$. In the light of these results we accept $\mathrm{H} 4$.

The indirect effect of discount offers includes the mediating role of perceived risk on the effect of discount offers on purchase intentions. Thus, it shows the effects of discount offers on purchase intentions through the perceived risk of consumers. The numerical expression of relative indirect effects of different discount offers through perceived risk is the product of regression coefficients in Model 2 and Model 3. Due to the non-normal sampling distribution of regression coefficients, a bootstrap confidence interval with 5,000 bootstrap samples is applied (Hayes \& Preacher, 2013). The calculations of the indirect effects and the corresponding results are presented in the following equations:

Discount $_{\text {Mid }}=\mathrm{a} 1 \mathrm{~b}=-1.000(-0.331)=0.331$

Discount $_{\text {High }}=\mathrm{a}_{2} \mathrm{~b}=-2.173(-0.331)=0.720$

The significance of the relative indirect effects is confirmed by checking the confidence intervals for different discount offers. The results are summarized in Table 5. 
Table 5. Indirect Effects of Discount Offers on Purchase Intentions

\begin{tabular}{|c|c|c|c|c|}
\hline & \multicolumn{4}{|c|}{ Discount Level } \\
\hline & Effect & Boot SE & Boot LLCI & Boot ULCI \\
\hline Discountmid $\mathrm{X}_{1}$ & 0.3314 & 0.0529 & 0.2309 & 0.4388 \\
\hline DiscountHigh $\mathrm{X}_{2}$ & 0.7200 & 0.1070 & 0.5092 & 0.9224 \\
\hline
\end{tabular}

The confidence intervals for Discount Mid $_{\text {are }}$ reported as $95 \% \mathrm{CI}=$ 0.2339 to 0.4388 . As the confidence interval does not include any zero value and both values are positive, this leads us to conclude that there is a significant and positive indirect effect of Discountmid on purchase intentions through the perceived risk of consumers. Similarly, the confidence intervals for Discount High are reported as $95 \%$ CI $=0.5092$ to 0.9224 . As the confidence interval does not include any zero value and both values are positive, again this leads us to conclude that there is a significant and positive indirect effect of Discount $H_{i g h}$ on purchase intentions through the perceived risk of consumers. In the light of these findings, we can conclude that there is a significant mediating role of perceived risk on the relationship between discount offers and the purchase intentions of consumers. Thus, different levels of discount offer affect positively the purchase intentions through the perceived risk of consumers. However, this mediating effect of perceived risk is a partial one since the total and direct effects of discount offers on purchase intentions are different from zero and statistically significant. These results lead us to accept $\mathrm{H6}$ and H7. The graphical representation of the direct and indirect effects of discount offers on purchase intentions are summarized in Figure 1.

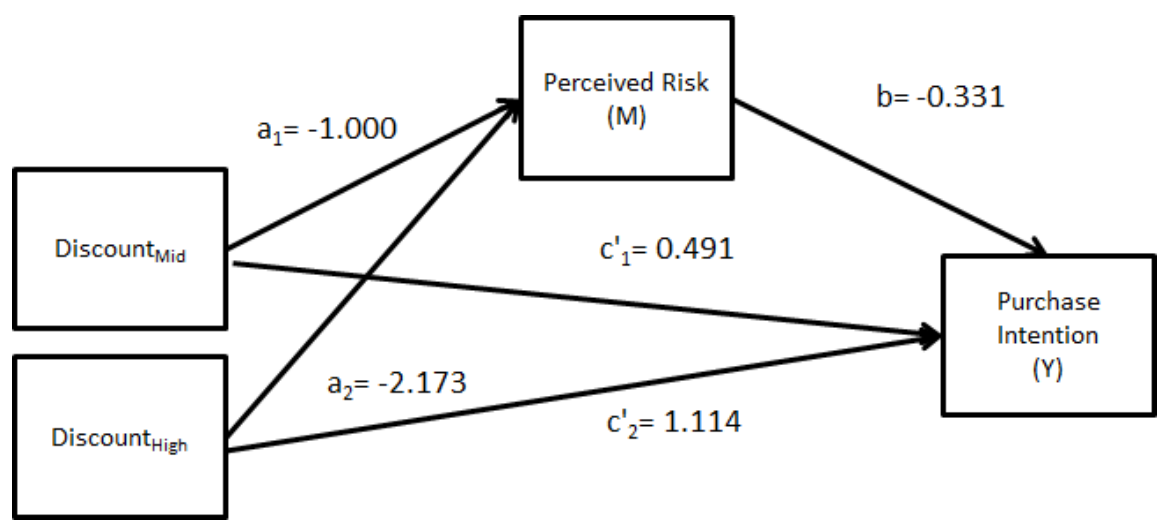

Figure 1. Direct and Indirect Effects of Discount Offer on Purchase Intentions 


\section{Moderating Role of Offer Recency on the Effect of Perceived Risk on Purchase Intentions}

The results of the analysis, which targets to measure the moderating role played by the offer recency on the effect of perceived risk on purchase intentions, confirmed that this effect is contingent on the offer recency level by generating significant interaction effects for both OfferMid-Term and OfferEarly Bird situations $(\mathrm{y}=0.2498, \mathrm{p}<0.001$ and $\mathrm{y}=0.5154, \mathrm{p}<0.001)$. As suggested by Aiken and West (1991), the calculation of interaction effect is made by computing the slopes -1 and +1 of the offer recency. The results of this interaction effect is summarized in Table 6 where the product of perceived risk and offer recency resulted in the generation of higher levels of purchase intentions for both OfferMid-Term and OfferEarly-Bird compared to Offerspot.

Table 6. Moderation Effect of Offer Recency

\begin{tabular}{lcccccc}
\hline \multirow{7}{*}{ Predictor } & \multicolumn{7}{c}{ DV= Purchase Intention (Y) } & & & \\
\cline { 2 - 7 } & Coefficient & SE & $\mathrm{t}$ & $\mathrm{p}$ & $95 \%$ CI LL & 95\% CI UL \\
\hline $\begin{array}{l}\text { Perceived Risk } \\
\left(\mathrm{b}_{1}\right)\end{array}$ & -0.6292 & 0.4490 & -13.9990 & $<.001$ & -.7175 & -.5410 \\
OfferMid-Term $\left(\mathrm{b}_{2}{ }^{1}\right)$ & -0.5505 & 0.1511 & -3.6440 & $<.001$ & -.8472 & -.2539 \\
OfferEarly-Bird $\left(\mathrm{b}_{2}{ }^{2}\right)$ & -0.6643 & 0.1379 & -4.8159 & $<.001$ & -.9351 & -.3935 \\
& & & & & & \\
Interaction $\left(\mathrm{b}_{3}{ }^{1}\right)$ & 0.2498 & 0.4730 & 5.2774 & $<.001$ & .1569 & .3428 \\
Interaction $\left(\mathrm{b}_{3}{ }^{2}\right)$ & 0.5154 & 0.0432 & 11.9308 & $<.001$ & .4306 & .6002 \\
\hline
\end{tabular}

The graphical representation of the conditional effects is presented in Figure 2. In cases of spot offers, the differential effect of perceived risk level is high on purchase intentions. However, this difference starts to shrink when consumers are exposed to the cases of OfferMid-Term and OfferEarly-Bird. Thus, the effect of perceived risk on purchase intentions changes due to the offer recency level exposed. In the light of these findings and significant interaction effects, we conclude that the offer recency moderates the effect of perceived risk on purchase intentions of consumers. Thus, we accept H8. 


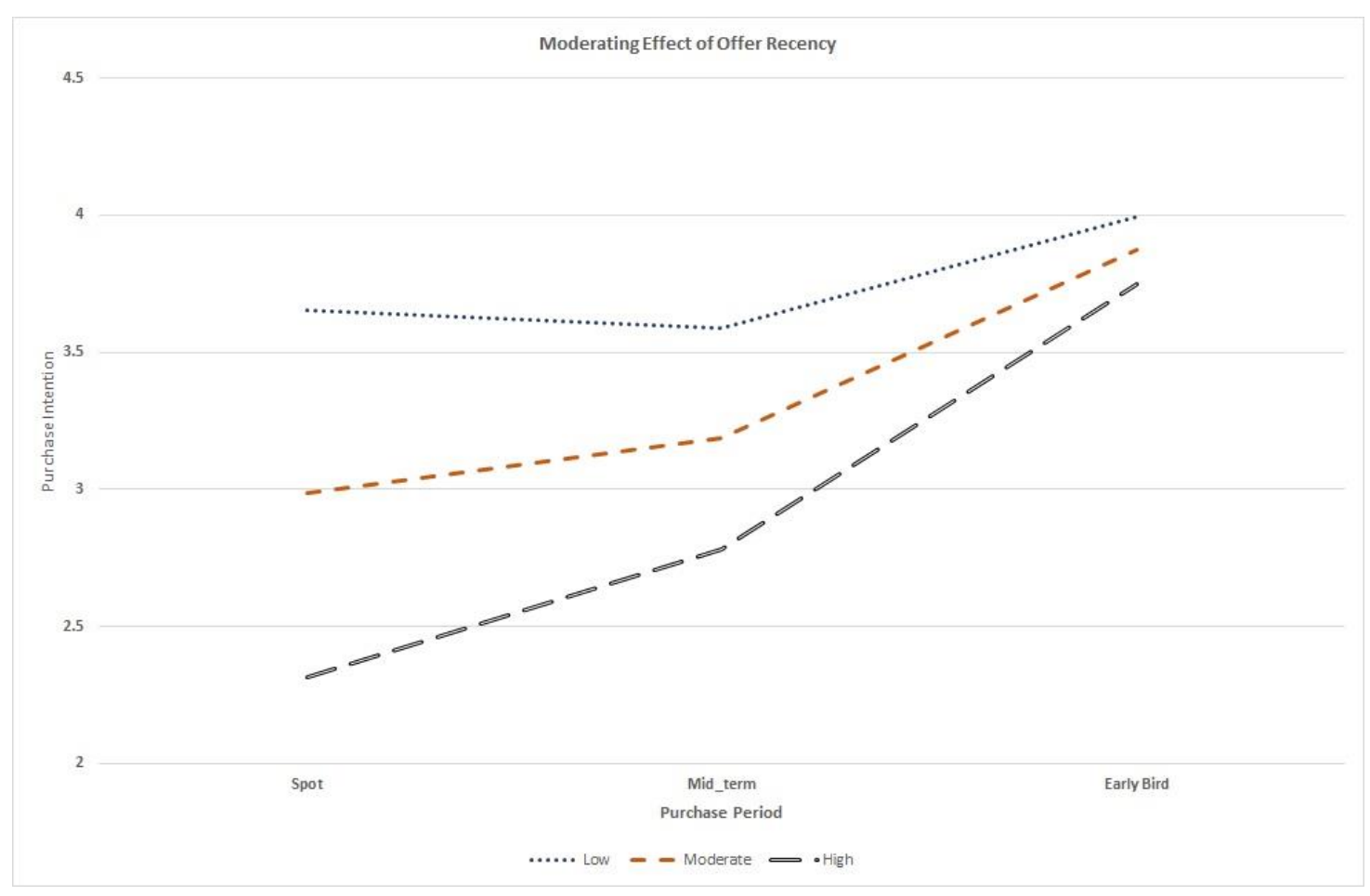

Figure 2. Interaction Effect of Moderation

\section{The Relative Conditional Indirect Effect of Discount Level on Purchase Intentions}

The conditional indirect effect of discount level on purchase intentions covers the moderated mediation role of perceived risk on this effect. In order to test this effect, we measure the indirect effects of discount levels on three different levels of perceived risk, namely low (-1 SD), average (mean) and high (+1 SD) levels. The result of this analysis is summarized in Table 7.

When consumers are offered middle level discounts (Discount $\mathrm{Mid}$ ), the conditional relative indirect effect of this discount level on purchase intentions through the perceived risk is the highest in cases where the offer is done one week earlier (Offerspot) than the check-in date $(0.63,95 \%$ $\mathrm{CI}=0.5177$ to 0.7366 ). On the other hand, when the offer time is three months earlier than the check-in date (OfferMid-Term), the indirect effect of

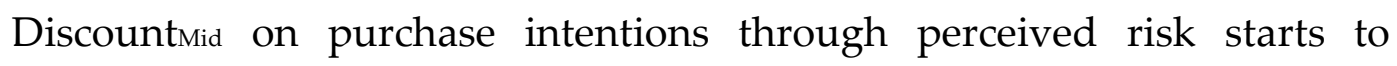
decrease and it is weaker compared to Offerspot $(0.38,95 \% \mathrm{CI}=0.2673$ to 0.4931). Similarly, when the offer time is six months earlier than the checkin date (OfferEarlyBird), then the conditional relative indirect effect of this 
discount level on purchase intentions through the perceive risk is the lowest compared to both Offerspot and Offermid-Term $(0.11,95 \% \mathrm{CI}=0.0434$ to 0.1839). The index of moderated mediation was calculated in order to test the significance of these differences and consequently to confirm the conditional relative indirect effect of Discountmid on purchase intentions through perceived risk. The results of this calculation confirmed the significant moderated mediation effect of offer recency for both OffermidTerm $(-0.25,95 \% \mathrm{CI}=-0.3218$ to -0.1814$)$ and OfferEarly Bird $(-0.52,95 \% \mathrm{CI}=$ -0.6097 to -0.4204 ) cases compared to Offerspot.

Table 7. Results of the Moderated Mediation Analysis

\begin{tabular}{|c|c|c|c|c|c|}
\hline \multirow{3}{*}{$\begin{array}{c}\text { Discount } \\
\text { Level }\end{array}$} & \multirow{3}{*}{ Period } & \multicolumn{4}{|c|}{ Conditional Relative Indirect Effect of Discount Level on } \\
\hline & & \multicolumn{4}{|c|}{ Purchase Intentions } \\
\hline & & Coefficient & SE & $95 \%$ CI LL & $95 \%$ CI UL \\
\hline \multirow{3}{*}{ Discountmid } & Spot (-1 SD) & 0.6292 & 0.0566 & 0.5177 & 0.7366 \\
\hline & $\begin{array}{l}\text { Mid-Term } \\
\text { (M) }\end{array}$ & 0.3794 & 0.0574 & 0.2673 & 0.4931 \\
\hline & $\begin{array}{l}\text { Early Bird } \\
(+1 S D)\end{array}$ & 0.1138 & 0.0360 & 0.0434 & 0.1839 \\
\hline \multirow{3}{*}{ DiscountHigh } & Spot $(-1 \mathrm{SD})$ & 1.3672 & 0.0968 & 1.1683 & 1.5487 \\
\hline & $\begin{array}{l}\text { Mid-Term } \\
\text { (M) }\end{array}$ & 0.8244 & 0.1152 & 0.5944 & 1.0446 \\
\hline & $\begin{array}{l}\text { Early Bird } \\
(+1 S D)\end{array}$ & 0.2473 & 0.0772 & 0.0951 & 0.3922 \\
\hline
\end{tabular}

The second part of Table 7 shows the results of the analysis related to the conditional relative indirect effect of Discount High $_{\text {on }}$ purchase intentions through the perceived risk. This conditional indirect effect is the highest in cases where the offer is done one week earlier (Offerspot) than the check-in date $(1.37,95 \% \mathrm{CI}=1.1683$ to 1.5487$)$. On the other hand, when the offer time is three months earlier than the check-in date (OffermidTerm), the indirect effect of Discount ${ }_{H i g h}$ on purchase intentions through perceived risk starts to decrease and it is weaker compared to Offerspot (0.82, 95\% CI $=0.5944$ to 1.0446$)$. Similarly, when the offer time is six months earlier than the check-in date (OfferEarlyBird), then the conditional relative indirect effect of this discount level on purchase intentions 
through the perceived risk is the lowest compared to both Offerspot and OfferMid-Term $(0.25,95 \% \mathrm{CI}=0.0951$ to 0.3922$)$. As it is done in previous analysis, the index of moderated mediation was calculated in order to test the significance of these differences and consequently to confirm the conditional relative indirect effect of DiscountHigh on purchase intentions through perceived risk. The results of this calculation confirmed the significant moderated mediation effect of offer recency for both OffermidTerm $(-0.54,95 \% \mathrm{CI}=-0.6889$ to -0.4024$)$ and OfferEarly Bird $(-0.52,95 \% \mathrm{CI}=$ -0.6097 to -0.4204$)$ cases compared to Offerspot. In the light of these findings, $\mathrm{H} 9$ can be accepted.

\section{DISCUSSION AND CONCLUSION}

The objective of this study was to measure the effect of dynamic pricing applications on the purchase intentions of consumers by taking into consideration the moderated mediation role of perceived risk by offer recency. The study involved several measurement models to explore the underlying dynamics between discount offers, perceived risk, offer recency and purchase intentions. The results of the study lead to several conclusions and contributions which need to be elaborated vis-a-vis to the previous findings in the literature.

One of the findings in this study is related with the direct effects of discount offers on the customers' purchase intentions. In line with the expectations and findings in the existing literature, discount offers are found to have positive direct effects on purchase intentions (Bakırtaş, 2013; Rizwan et al., 2013). Moreover, the results confirmed that the level of discount determines the level of purchase intentions in a way that more attractive discounts generate higher level of purchase intentions. This result also finds some support in the existing literature (Palazon \& Delgado-Ballester, 2009). However, there are also studies which report an inverted $U$ type explanation rather than linear relationship between the benefit levels and consumer behavior in the context of sales promotions (Grewal et al., 1998). The results of this study also confirm the significant negative effect of discount offers on perceived risk of consumers. Increasing levels of discount leads to lower levels of perceived risk and this is in line with the findings in the existing literature (Garretson \& Clow, 1999).

Another finding in this study, which is in line with the results of the existing studies in the literature, is the direct negative effect of perceived 
risk on purchase intentions. Parallel to the existing studies, when the perceived risk of consumers increases, their purchase intentions become lower. This result finds strong support in the previous studies which are focused on this subject (Ashoer \& Said, 2016; Xie, 2017; Wood \& Scheer, 1996).

There are two important contributions of this study to the existing literature. The first one is related with the mediating role of perceived risk on the effect of discount offers on purchase intention in a way that different levels of discount offers affect positively the purchase intentions through the perceived risk of consumers. Compared to cases with no discount at all, the differential positive direct effects of DiscountMid and DiscountHigh on purchase intentions start to decrease when the perceived risk of consumers mediates this effect. This result is an important contribution of this study to the existing literature since there is a lack of studies focusing on the mediating effect. A second important contribution of this study is that this mediating role of perceived risk is moderated by the offer recency, which leads to consumers' inter temporal decisions and plays a moderated mediation role on the effect of discount offers on purchase intentions. This finding also contributes to the existing literature by filling a gap in the relationship between dynamic pricing, perceived risk and timing factor.

\section{PRACTICAL IMPLICATIONS}

The results of this study lead to several practical implications. First, one of the results indicate that offering a discount compared to not offering it, increases the intention of consumers to purchase the ski resort holiday package. Moreover, the level of discount determines the level of purchase intention. Those hotels which compete in a highly competitive markets and offer holiday packages for international customers need to acquire them as soon as possible, in order to maximize the occupancy rate. They need to find the optimum level of discount which will boost the sales without harming the profitability and, eventually, lead to maximization of occupancy rate at the earliest time possible.

Another finding of this study is the negative effect of perceived risk on purchase intentions. When consumers feel uncertainties about the performance of the hotel, this will increase their perceived risk and eventually their purchase intention will be lower. It is found that the perceived risk level also mediates the effect of discount offers on purchase 
intentions. When consumers perceive higher levels of risk, the effect of discounts on purchase intentions becomes weaker. In order to cope with this challenge, marketers need to encourage their satisfied customers to share their opinions with other consumers in the market as much as possible. As the opinion of other consumers is an important determinant of decision making in hotel selections, these opinions are expected to help customers to eliminate the uncertainties and consequently lower the perceived risk levels. Thus, all platforms including social media, forums and web sites should be used by the marketers to boost customer opinion sharing. Customers should be encouraged and incentivized to share their opinions in these platforms.

The timing of the offer was also found as an important factor influencing the effect of discounts on purchase intentions through perceived risk level. In comparison with no discount cases, the positive effect of discounts on purchase intentions diminishes in all discount levels due to the inter-temporal effect on perceived risk levels. Marketers should try to adjust their marketing mix to eliminate the uncertainties of consumers derived from purchasing the holiday package earlier. First, a direct solution is to offer insurance to the international customers, as some tourism agencies already provide. Marketers may engage in such insurance programs or work with agencies which provide such insurances in order to decrease the perceived risk level. On the other hand, if there is no such program, as the return of the package becomes impossible after a certain period, depending on the cancellation and refund policy, one of the immediate tools that can be provided to those consumers, who won't be able to travel, is an opportunity to sell their holiday package. The hotel may create a late market program which will start 7 days earlier before the check-in date and if there are no rooms available in the hotel, the hotel may provide original buyers the opportunity to sell their package at a discounted price. This program may provide value for all parties including the original owner of the package, the hotel and the prospect late buyer.

As a result, hotel managers, who target to maximize the occupancy rate in an optimum way, need to implement a dynamic pricing policy which will create and sustain a balance between perceived performance risk of purchase in a particular hotel, inter temporal risk perceptions and the discounts offered in order to maximize the expected value for both their customers and their hotel. 


\section{LIMITATIONS AND SUGGESTIONS FOR FUTURE RESEARCH}

This study was conducted in the tourism context and the type of product employed in the experimental design was the international ski resort holiday package. This is a limitation for the study which leads to some generalizability issues. As a direction for future studies, it is suggested to conduct the same study in different contexts, for different products and in a cross-country setting in order to increase the generalizability of the study and provide deeper understanding of the underlying dynamics.

\section{REFERENCES}

Abrate, G., Fraquelli, G., \& Viglia, G. (2012). Dynamic pricing strategies: Evidence from European hotels. International Journal of Hospitality Management, 31, 160-168.

Adenso-Diaz, B., Lozano, S., \& Palacio, A. (2017). Effects of dynamic pricing of perishable products on revenue and waste. Applied Mathematical Modelling, 45, 148-164.

Aiken, L. S., \& West, S. G. (1991). Multiple regression: Testing and interpreting interactions. Newbury Park: Sage.

Arrow, K. J. (1962). The economic implications of learning by doing. Review of Economic Studies, 29(3), 155-173.

Ashoer, M., \& Said, S. (2016). The impact of perceived risk on consumer purchase intention in Indonesia. A Social Commerce Study Proceeding of the International Conference on Accounting, Management, Economics and Social Sciences (ICAMESS), 113.

Badinelli, R. (2000). An optimal, dynamic policy for hotel yield management. European Journal of Operational Research, 121, 476-503.

Bakırtaş, H. (2013). Impact of sales promotion on purchase decision of consumers: An application in tourism sector. International Journal of Human Sciences, 10(1), 676694.

Bartels, D. M., \& Urminsky, O. (2015). To know and to care: How awareness and valuation of the future jointly shape consumer spending. Journal of Consumer Research, 41(6), 1469-1485.

Bass, F. M. (1969). A new product growth model for consumer durables. Management Science, 15(4), 215-227.

Bauer, R. A. (1960). Consumer behavior as risk taking. In R. Hancock (Ed.), Dynamic Marketing for a Changing World (pp. 389-398), Proceedings of 43rd Conference, American Marketing Association.

Bayoumi, A. E., Saleh, M., Atiya, A. F., \& Aziz, H. A. (2013). Dynamic pricing for hotel revenue management using price multipliers. Journal of Revenue and Pricing Management, 12(3), 271-285.

Bhukya, R., \& Singh, S. (2015). The effect of perceived risk dimensions on purchase intention: An empirical evidence from Indian private labels market. American Journal of Business, 30(4), 218-230.

Bull, P. (1997). Mass tourism in the Balearic Islands: An Example of concentrated dependence. In D. Lockhart and D. Dukakis-Smith (Eds.), Island Tourism: Trends and Prospects (pp.137-151). London: Pinter. 
Campbell, M. C. \& Goodstein, R.C. (2001). The Moderating Effect of Perceived Risk on Consumers' Evaluations of Product Incongruity: Preference for the Norm. Journal of Consumer Research, 28 (December), 439-449.

Chakrabarti, S., \& Baisya, R. K. (2009). The influences of consumer innovativeness and consumer evaluation attributes in the purchase of fashionable ethnic wear in India. International Journal of Consumer Studies, 33(6), 706-714.

Chandran, S. \& Morwitz, V. G. (2005). Effects of Participative Pricing on Consumers' Cognitions and Actions: A Goal Theoretic Perspective. Journal of Consumer Research, 32 (September), 249-259.

Chang, T. Z., \& Wildt, A. R. (1994). Price, product information and purchase intention: An empirical study. Journal of the Academy of Marketing Science, 22(1), 16-27.

Chao, R. F., \& Liao, P. C. (2016). The impact of brand image and discounted price on purchase intention in outlet mall: Consumer attitude as mediator. The Journal of Global Business Management, 12(2), 120-128.

Chenavaz, R., Carrier, L. P., Etienne, L., \& Paraschiv, C. (2011). Dynamic pricing in management science. Journal of Economics Studies and Research, 1-16.

Corgel, J. B. (2004). Predictive powers of hotel cycles. Real Estate Issues, 28(4), 32-36.

Cox, D. F., \& Rich, S. U. (1964). Perceived risk in consumer decision making: The case of telephone shopping. Journal of Marketing Research, 1(4), 32-39.

Croes, R., \& Semrad, K. J. (2012). Does discounting work in the lodging industry? Journal of Travel Research, 51(5), 617-631.

Cross, R., Higbie, J., \& Cross, D. (2009). Revenue management's renaissance. Cornell Hospitality Quarterly, 50(1), 56-81.

Dasu, S., \& Tong, C. (2010). Dynamic pricing when consumers are strategic: Analysis of posted and contingent pricing schemes. European Journal of Operational Research, 204(3), 662-671.

Dimicco, J. M., Maes, P., \& Greenwald, A. (2003). Learning curve: A simulation-based approach to dynamic pricing. Electronic Commerce Research, 3(3/4), 245-276.

Dodds, W. B., \& Monroe, K. B. (1985). The effect of brand and price information on subjective product evaluation. Advances in Consumer Research, 12, 85-90.

Dong, L., Kouvelis, P., \& Tian, Z. (2008). Dynamic pricing and inventory control of substitute products. Manufacturing and Service Operations Management, 11(2), 317339.

Doss, C., McPeak, J., \& Barrett, C. (2006). Interpersonal, intertemporal and spatial variation in risk perceptions: Evidence from East Africa. Working Papers 948, Economic Growth Center, Yale University.

Economides, N. (1996). The economics of networks. International Journal of Industrial Organization, 14(2), 673-699.

Elmaghraby, W., \& Keskinocak, P. (2003). Dynamic pricing in the presence of inventory considerations: Research overview, current practices, and future directions. Management Science, 49(10), 1287-1309.

Enz, C., Canina, L., \& Lomanno, M. (2009) Competitive pricing decisions in uncertain times. Cornell Hospitality Quarterly, 50(3), 325-341.

Enz, C. A., Canina, L., \& Lomanno, M. V. (2004). Why discounting doesn't work. The Center for Hospitality Research Reports, 4(7), 1-28.

Farahmand, A., \& Chatterjee, C. (2008). The case for dynamic pricing. Hospitality Upgrade, $154-155$

Feng, Y., \& Xiao, B. (2000). A continuous-time yield management model with multiple prices and reversible price changes. Management Science, 46(5), 644-657. 
Gallego, G., \& Ryzin, G. (1994). Optimal dynamic pricing of inventories with stochastic demand over finite horizons. Management Science, 40, 999-1020.

Garretson, J. A, \& Clow, K. E. (1999). The influence of coupon face value on service quality expectations, risk perceptions and purchase intentions in the dental industry. Journal of Services Marketing, 13(1), 59-72.

Gefen, D. (2002). Reflections on the dimensions of trust and trustworthiness among online consumers. ACM SIGMIS Database, 33(3), 38-53.

Grewal, D., Krishnan, R., Baker, J., \& Borin, N. (1998). The effect of store name, brand name and price discounts on consumers' evaluations and purchase intentions. Journal of Retailing, 74, 331-352.

Hashim, N.A., Husin, Z., Othman, I.L., \& Zain, A.Y. (2017). The roles of perceived risks and price on the purchase intention of China-made home appliances among career women in Malaysia. International Journal of Management Studies (IJMS), 24(1), 169-185.

Haws, K., \& Bearden, W. (2006). Dynamic pricing and consumer fairness perceptions. Journal of Consumer Research, 33, 304-311.

Hayes, A. F. (2018). Introduction to mediation, moderation, and conditional process analysis: A regression-based approach (2nd ed.). New York: The Guildford Press.

Hayes, F. A., \& Preacher, K. J. (2013). Statistical mediation analysis with a multi categorical independent variable. The British journal of mathematical and statistical psychology, 67(3), 451-470.

Heskett, J. L., Jones, T. O., Loveman, G. W., Sasser, E. W., \& Schlesinger, L. A. (1994). Putting the service-profit chain to work. Harvard Business Review, 72(2), 164-174.

Hong, I., \& Cha, H. S. (2013). The mediating role of consumer trust in an online merchant in predicting purchase intention. International Journal of Information Management, 33, 927-939.

Jorgensen, S. (1986). Optimal dynamic pricing in an oligopolistic market: A survey, dynamic games and applications in economics. In T. Basar (ed.). Lecture Notes in Economics and Mathematical Systems (vol. 265, pp. 179-237). Berlin: Springer.

Kim, B. K., \& Zauberman, G. (2009). Perception of anticipatory time in temporal discounting. Journal of Neuroscience, Psychology and Economics, 2(2), 91-101.

Kim, L. H., Kim, D. J., \& Leong, J. K. (2005). The effect of perceived risk on purchase intention in purchasing airline tickets online. Journal of Hospitality $\mathcal{E}$ Leisure Marketing, 13(2), 33-53.

Kimes, S. E. (2002). Perceived fairness of yield management. The Cornell Hotel and Restaurant Administration Quarterly, 43, 21-30.

Koide, T., \& Ishii, H. (2005). The hotel yield management with two types of room prices, overpurchase and cancellations. International Journal of Production Economics, 9394, 417-428.

Kopalle, P. K., Mela, C. F., \& Marsh, L. (1999). The dynamic effect of discounting on sales: empirical analysis and normative pricing implications. Management Science, 18(3), 317-332.

Levin, Y., McGill, J., \& Nediak, M. (2009). Dynamic pricing in the presence of strategic consumers and oligopolistic competition. Management Science, 55(1), 32-46.

Lin, T., \& Fang, C. (2006). The effects of perceived risk on the Word-of-Mouth Communication DYAD. Social Behavior and Personality: An international journal, 34, 1207-1216.

Liu, Q., \& Ryzin, G. (2008). Strategic capacity rationing to induce early purchases. Management Science, 54(6), 1115-1131. 
Liu, X., Tang, O., \& Huang, P. (2008). Dynamic pricing and ordering decision for the perishable food of the supermarket using RFID technology. Asia Pacific Journal of Marketing and Logistics, 20(1), 7-22.

Mahajan, V., Muller, E., \& Bass, F. M. (1990). New product diffusion models in marketing: A review and directions for research. The Journal of Marketing, 54(8), 126.

Mitchell, V.W. (1999). Consumer perceived risk: conceptualizations and models. European Journal of Marketing, 33(1/2), 163-195.

Mitchell, V. W., \& Vassos, V. (1997). Perceived risk and risk reduction in holiday purchases: A cross-cultural and gender analysis. Journal of Euromarketing, 6(3), 4779.

Mitra, K., Reiss, M. C., \& Capella, L. M. (1999). An examination of perceived risk, information search and behavioral intentions in search, experience and credence services. Journal of Services Marketing, 13(3), 208-228.

Murray, K. B. (1991). A test of services marketing theory: consumer information acquisition activities. Journal of Marketing, 55(1), 11-25.

Namboodiri, V. M. K., Mihalas, S., Marton, T. M., \& Shuler, M. G. H. (2014). A general theory of intertemporal decision-making and the perception of time. Frontiers in Behavioral Neuroscience, 8, 1-18.

Noseworth, T. J. \& Trudel, R. (2011). Looks Interesting, but What Does It Do? Evaluation of Incongruent Product Form Depends on Positioning. Journal of Marketing Research, 48 (6), 1008-1019.

Palazon, M., \& Delgado-Ballester, E. (2009). Effectiveness of price discounts and premium promotion. Psychology \& Marketing, 26(12), 1108-1129.

Qu, H., Xu, P., \& Tan, A. (2002). A simultaneous equations model of the hotel room supply and demand in Hong Kong. International Journal of Hospitality Management, 21, 455-462.

Rizwan, M., Irshad, Q., Ali, K., Nadir, M., \& Ejaz, M. (2013). Impact of sales promotional tools on purchase intentions. International Journal of Management Sciences and Business Research, 2(1), 36-49.

Roehl, W. S., \& Fesenmaier, D. R. (1992). Risk perceptions and pleasure travel: An exploratory analysis. Journal of Travel Research, 30(4), 17-26.

Rohani, A. (2012). Impact of dynamic pricing strategies on consumer behavior. Journal of Management Research, 4(4), 143-159.

Sahay, A. (2007). How to reap higher profits with dynamic pricing. MIT Sloan Management Review, 48, 53-60.

Santini, F. O., Sampaio, C. H., Perin, M. G., \& Vieira, V. A. (2015). An analysis of the influence of discount sales promotion in consumer buying intent and the moderating effects of attractiveness. Revista de Administracao, 50(4), 416-431.

Shapiro, J. M. (2005). Is there a daily discount rate? Evidence from the food stamp nutrition cycle. Journal of Public Economics, 89(2-3), 303-325.

$\mathrm{Su}$, X. (2007). Intertemporal pricing with strategic customer behavior. Management Science, 53(5), 726-741.

Sweeney, J. C., Soutar, G. N., \& Johnson, L. W. (1999). The role of perceived risk in the quality-value relationship: A study in a retail environment. Journal of Retailing, 75(1), 77-105.

Tan, S. J. (1999). Strategies for reducing consumers' risk reduction aversion in Internet shopping. Journal of Consumer Marketing, 16(2), 163-180.

Taylor, A. G. (2001). Coupon response in services. Journal of Retailing, 77, 139-151. 
Teng, L. (2009). A comparison of two types of price discounts in shifting consumers' attitudes and purchase intentions. Journal of Business Research, 62, 14-21.

Viglia, G., Mauri, A., \& Carricano, M. (2016). The exploration of hotel reference prices under dynamic pricing scenarios and different forms of competition. International Journal of Hospitality Management, 52, 46-55.

Wood, C. M., \& Scheer, L. K. (1996). Incorporating perceived risk models of consumer deal assessment and purchase intent. Advances in Consumer Research, 23, 399-404.

Xie, C. (2017). The influence of perceived risk on purchase intention - A case study of Taobao online shopping of fresh fruit. Asian Agricultural Research, 9(5), 30-35.

Yi, Y., \& Yoo, J. (2011). The long-term effects of sales promotions on brand attitude across monetary and non-monetary promotions. Psychology and Marketing, 28, 879-896.

Zauberman, G. \& Urminsky, O. (2016). Consumer intertemporal preferences. Current Opinion in Psychology, 10, 136-141.

Zhao, W., \& Zheng, Y. (2000). Optimal dynamic pricing for perishable assets with nonhomogeneous demand. Management Science, 46, 375-388. 